\title{
Seismic response of reinforced concrete frames at different damage levels
}

\author{
Merangeli Morales-González ${ }^{1}$ Aidcer L. Vidot-Vega ${ }^{2}$
}

Received: 8 June 2016/Accepted: 24 January 2017/Published online: 7 February 2017

(C) The Author(s) 2017. This article is published with open access at Springerlink.com

\begin{abstract}
Performance-based seismic engineering is focused on the definition of limit states to represent different levels of damage, which can be described by material strains, drifts, displacements or even changes in dissipating properties and stiffness of the structure. This study presents a research plan to evaluate the behavior of reinforced concrete (RC) moment resistant frames at different performance levels established by the ASCE 41-06 seismic rehabilitation code. Sixteen RC plane moment frames with different span-to-depth ratios and three 3D RC frames were analyzed to evaluate their seismic behavior at different damage levels established by the ASCE 41-06. For each span-to-depth ratio, four different beam longitudinal reinforcement steel ratios were used that varied from 0.85 to $2.5 \%$ for the $2 \mathrm{D}$ frames. Nonlinear time history analyses of the frames were performed using scaled ground motions. The impact of different span-to-depth and reinforcement ratios on the damage levels was evaluated. Material strains, rotations and seismic hysteretic energy changes at different damage levels were studied.
\end{abstract}

Keywords ASCE 41-06 · Performance-based design · Reinforced concrete frames - Rotations - Seismic hysteretic energy

Aidcer L. Vidot-Vega

aidcer.vidot@upr.edu

1 Mechanical Analysis Department, Infotech Aerospace Services, 699 Industrial Avenue, Isabela 00662, Puerto Rico

2 Department of Engineering Science and Materials, University of Puerto Rico at Mayagüez, P.O. Box 9000, Mayagüez 00681, Puerto Rico

\section{Introduction}

Performance-based seismic engineering is focused on the definition of limit states to represent different levels of damage, which can be described by material strains, rotations, displacements or even changes in dissipating properties of the structure. ASCE 41-06 (2007) seismic rehabilitation code defines different damage levels such as: immediate occupancy (IO), life safety (LS) and collapse prevention $(\mathrm{CP})$. In the IO, the structure has minor cracks on non-structural elements. In the LS level, the structure is designed to have a residual stiffness and strength in all stories, with permanent drift. Finally, in the CP level, the structures have a minimal stiffness and strength in all stories, but columns and walls remains working. On this stage, non-structural components are damaged and the building is near to collapse (ASCE 41-06 2007). This code provides rotations at these levels that can be used for acceptance criteria when evaluating reinforced concrete elements using linear or nonlinear procedures.

This paper studies the response of reinforced concrete (RC) moment resistant frames under several seismic ground motions and evaluates different damage levels established by the ASCE 41-06 seismic rehabilitation standard using the rotation acceptance criteria for nonlinear procedures. The principal objective of this paper is to establish conclusions about different response parameters (e.g., materials strains and seismic hysteretic energy) that could be used in conjunction with rotations to define damage limit states and how the current ASCE 41-06 rotation limits could be improved. This study is accomplished by: (1) nonlinear time history analyses (NLTHA) of reinforced concrete plane moment resisting frames with different span-to-depth and longitudinal reinforcement steel ratios subjected to several scaled seismic ground 
motions; (2) nonlinear time history analyses of three 3D reinforced concrete frames. One of these frames was tested as part of the 15th WCEE (World Conference on Earthquake Engineering-2012); (3) detailed studies of the results obtained from the NLTHA focusing on the evaluation of material strains, rotations and seismic hysteretic energy changes at different damage limit states; and (4) evaluation of the ASCE 41-06 rotation limits.

\section{Plane reinforced concrete frame models}

In this paper, a total of 16 planar (2D) reinforced concrete frames with two bays and four stories were analyzed. Four different span-to-depth ratios $(\mathrm{L} / \mathrm{H})$ that varied from 7.5 to 12 were used. Span-to-depth ratios are defined as the length over the height of the beam. For each span-to-depth ratio, four different longitudinal reinforcement ratios were specified. The percentage of reinforcement steels were varied from 0.85 to $2 \%$ and from 1.0 to $2.5 \%$ for the first three $\mathrm{L} / \mathrm{H}$ ratios $(7.5,9$ and 10$)$ and for the $\mathrm{L} / \mathrm{H}=12$ ratio, respectively (Fig. 1). The column height for all plane frames was set to $3.05 \mathrm{~m}$, for a total structural height of $12.2 \mathrm{~m}$. A beam's length of $4.57 \mathrm{~m}$ was selected for frames with $\mathrm{L} / \mathrm{H}$ of 7.5 (frame 1), 9 (frame 2) and 10 (frame 3). For $\mathrm{L} / \mathrm{H}=12$ (frame 4) the beam's length was $6.1 \mathrm{~m}$. Beam section heights were the following: $609.6 \mathrm{~mm}$ (frame 1), $508 \mathrm{~mm}$ (frame 2 and 4) and $457.2 \mathrm{~mm}$ (frame 3). All beams have a width of $304.88 \mathrm{~mm}$ and transverse steel spacing of $102 \mathrm{~mm}$ (Fig. 1). All column sections had dimensions of $609.76 \mathrm{~mm} \times 609.76 \mathrm{~mm}$. Additional details are presented in Fig. 1. The frames were designed to follow a weak beam strong column mechanism.

\section{Three-dimensional frame models}

A total of three 3D RC frames were modeled. The first model of a 3D frame included in this paper was tested as part of the activities of the 15th World Conference on Earthquake Engineering (2012). This frame was used as reference frame to develop the other two models. The frame was composed of one story, one bay in each direction and slab until half the girder length, as shown in Fig. 2. The frame dimensions were: beam's length of $3.5 \mathrm{~m}$, girder's length of $4 \mathrm{~m}$ and columns of $3 \mathrm{~m}$ height. The beam's depth and width were 40 and $20 \mathrm{~cm}$, respectively. The column dimensions were $20 \mathrm{~cm} \times 20 \mathrm{~cm}$. The slab dimensions are shown in Fig. 2. Nine additional masses of $1200 \mathrm{~kg}$ were placed on this slab. Each mass was fixed to the slab using 4 bolts, 8 steel plates, 8 washers and 8 nuts which represents an additional mass of $36 \mathrm{~kg}$. Then, two additional 3D frames were included by modifying the

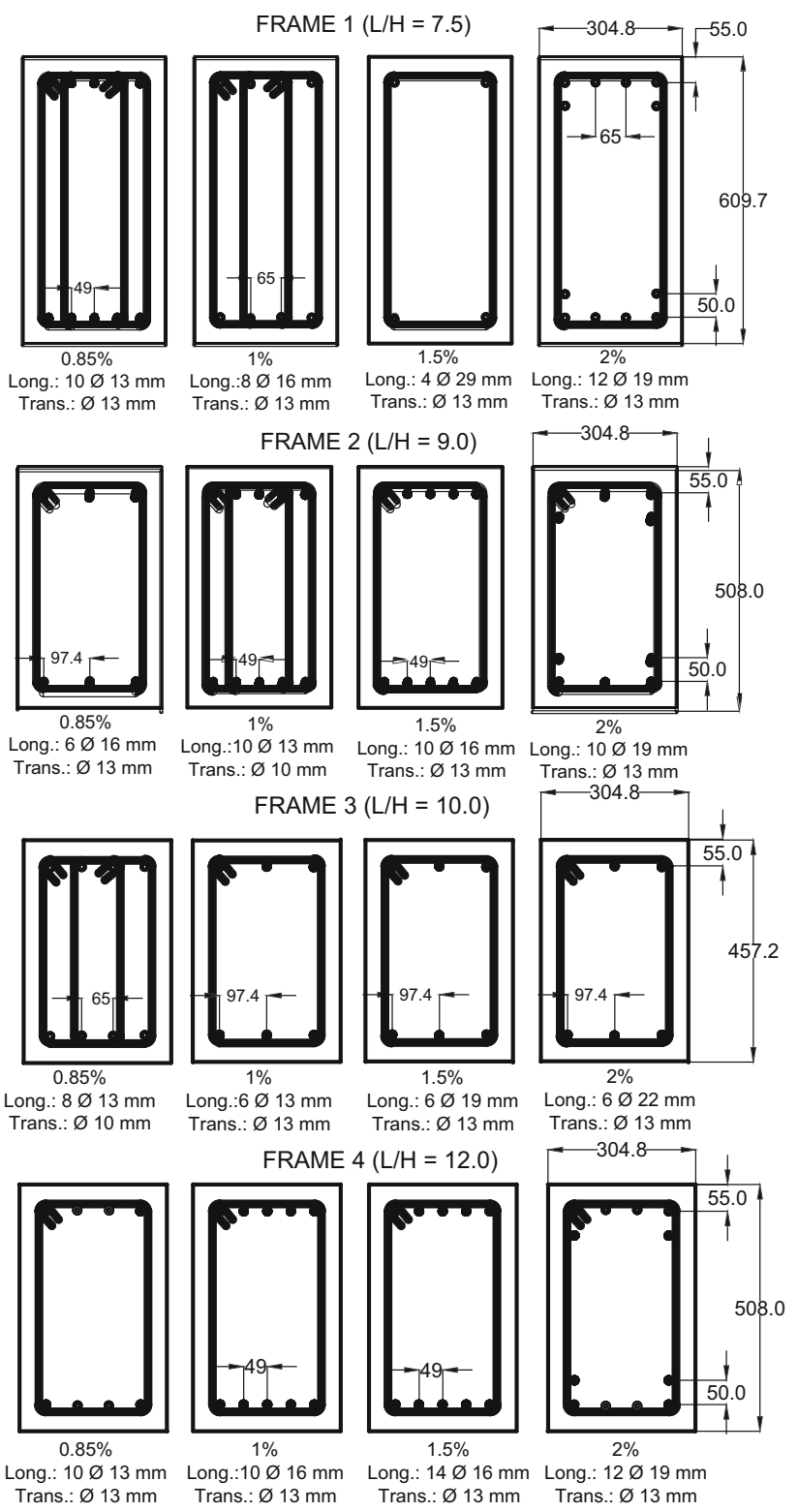

Fig. 1 Beam sections for 2D frames

beam and girder lengths to have one frame with lower span-to-depth ratio and one with higher span-to-depth ratio that the reference frame tested at the Conference. The dimensions of the beam and girders of these two models are shown in Fig. 2.

\section{Modeling approaches and materials}

All the beam and column sections for the 2D and 3D frames were modeled using the nonlinear fiber element approach. This approach consists of the division of each material that comprises the section into several fibers. A reinforced concrete section is divided in unconfined, 


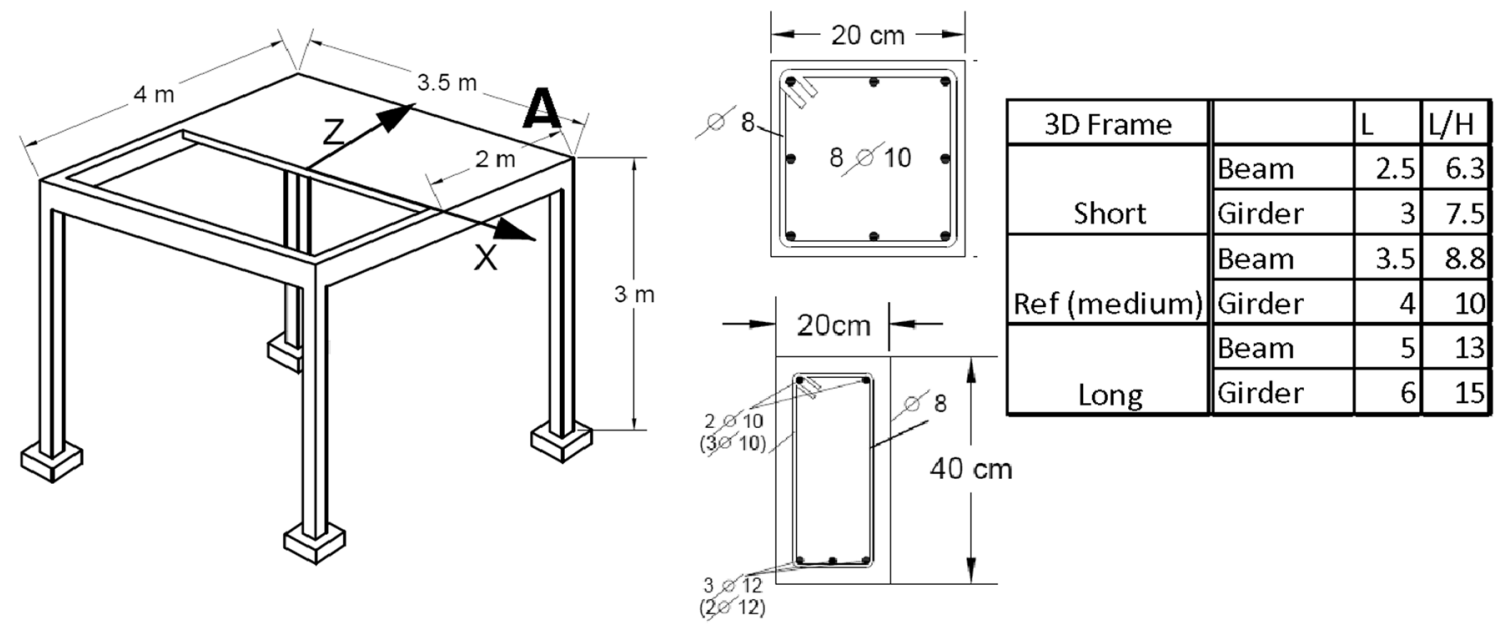

Fig. 2 General dimensions, beam and column sections of 3D models (adapted from 15th WCEE Blind Test Challenge Design Report 2012)

confined and steel fibers. The OpenSEES (McKenna et al. 2000) software platform was used to perform all the analyses. The Concrete 01 material based on the concrete constitutive model of Kent and Park (1971) with modifications performed by Karsan and Jirsa (1969) was used. Concrete 01 is a uniaxial material with degraded linear unloading/reloading and no tensile strength. The concrete confined strength and strains were calculated used the equations from Mander et al. (1988) concrete constitutive model. Unconfined concrete strain was defined as 0.002 . For the 2D frames, the concrete compressive strength for all elements was set to $32 \mathrm{MPa}$. For the 3D models, the concrete compressive strength was $30.03 \mathrm{MPa}$ for the beams and $35.63 \mathrm{MPa}$ for the columns. All the properties of the reference 3D frame were given by the 15th WCEE Blind Test Challenge Committee (15th WCEE Blind Test Challenge Design Report 2012). The uniaxial material reinforcing steel was used for the reinforcing steel. This model is based on the works performed by Mohle and Kunnath (2006) and Chang and Mander (1994). Steel yield strengths of $450 \mathrm{MPa}$ for all elements of the 2D frames and $561.67 \mathrm{MPa}$ for the 3D frames were used. All the elements (beams and columns) were modeled using the beam with hinges element (Scott and Fenves 2006) of the OpenSEES program. By using the beam with hinges element, it is considered that the plasticity of the element is concentrated at a specified plastic hinge length at the element ends. Elastic elements were used to model the frame joints. The joint element in the column has a length equal to half the beam depth. The joint element in the beam has a length equal to half the column height. Figure 3 shows an illustration of the joint modeling. This was done to obtain a better behavior of the beam-column joint by having a linear elastic section with the beam or column elastic stiffness (Priestley et al. 2007). The plastic hinge length for each element was calculated using Eqs. 1-2, from the methodology presented by Priestley et al. (2007). In these equations $L_{\mathrm{SP}}$ is the strain penetration length, $L_{\mathrm{C}}$ is the length from the critical section to the point of contraflexure, $d_{\mathrm{bl}}$ is the reinforcing steel longitudinal bar diameter, and $f_{\mathrm{u}}$ is ultimate steel strength.

$L_{\mathrm{P}}=k L_{\mathrm{C}}+L_{\mathrm{SP}} \leq 2 L_{\mathrm{SP}}$,

$L_{\mathrm{SP}}=0.022 f_{y} d_{b l}$,

$k=0.2 \frac{f_{u}}{f_{y}}-1 \leq 0.08$.

\section{Nonlinear time history analyses (NLTHA)}

\section{Plane frames (2D)}

For the nonlinear time history analyses of the plane frames, 7 seismic ground motions (Chi-Chi, Tabas, Kocaeli, Kobe, Northridge, Imperial Valley and Loma Prieta) were chosen from the Pacific Earthquake Engineering Research (PEER) database. These ground motions were made compatible with a design spectrum. The design spectrum was constructed using the parameters from ASCE 7-05 (2006). For the design spectrum, the values of the design spectral response acceleration parameter at short period (SDS), the design spectral response acceleration parameter at $1 \mathrm{~s}$ (SD1), and the long period transition period (TL) were equal to $0.812,0.421$, and $12 \mathrm{~s}$, respectively (Fig. 4). The spectrum values were obtained for a soil type D (ASCE 7-05 2006) and represent a structure in a moderate-to-high seismic region. The MATLAB ${ }^{\circledR}$ program ArtifQuakeLet (Suarez and Montejo 2007) was used to make the records compatible with the design spectrum which uses wavelet theory to match the response spectrum of each earthquake to the target spectrum. NLTHA were performed with the 

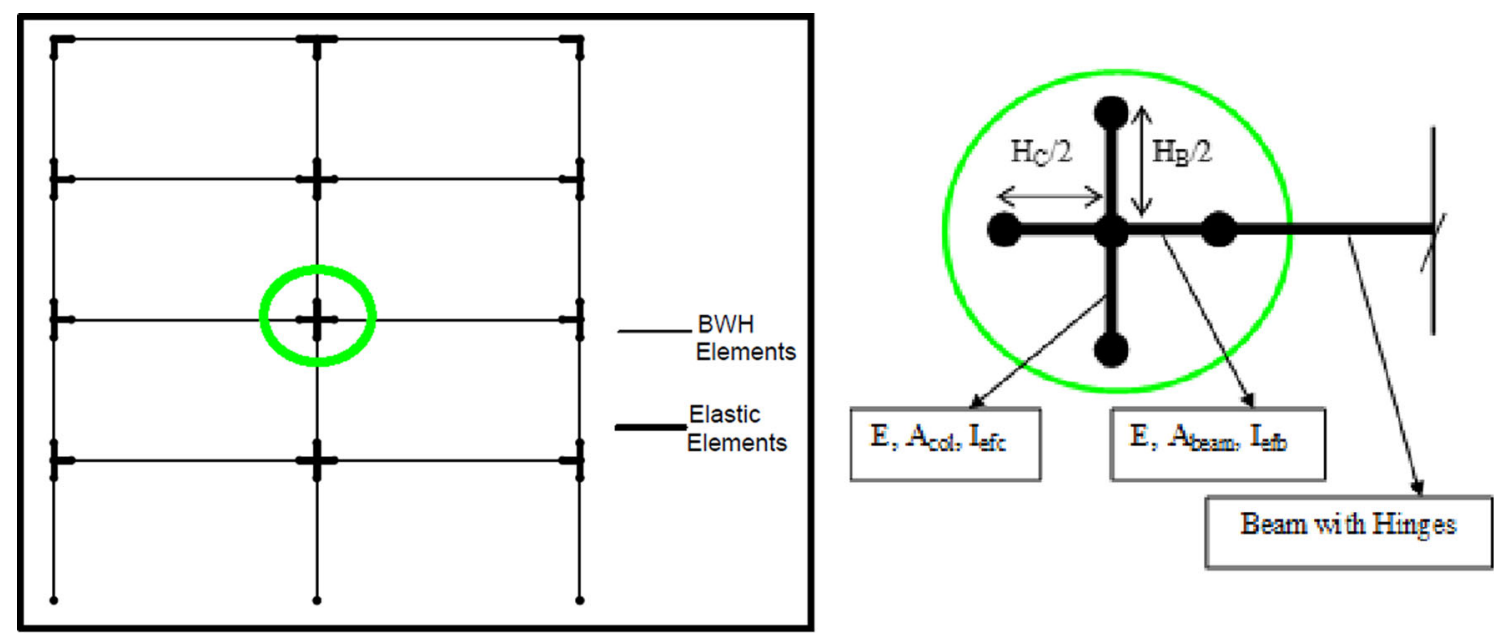

Fig. 3 Modeling of elements and joints for 2D frames

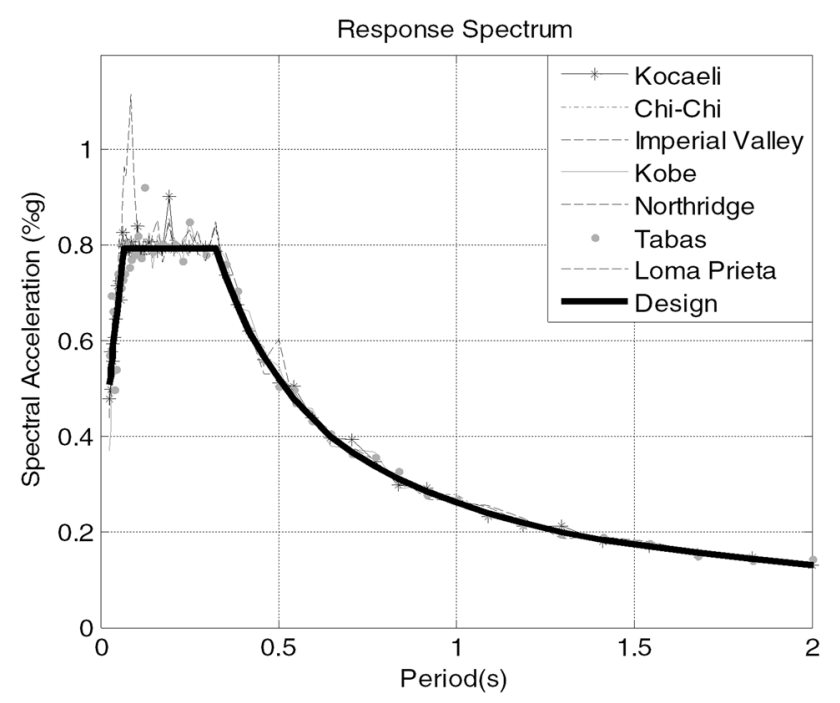

Fig. 4 Response spectrum with target design spectra for all earthquakes

ground motions scaled from 0.1 to $1.5 \mathrm{~g}$ in increments of 0.1 (15 analyses per earthquake per frame).

\section{D frames}

For the 3D frames, a seismic ground motion scaled to 4 intensity levels was used. This ground motion was provided by the 15th WCEE blind test committee. They selected two horizontal orthogonal components of a strong motion signal registered during the 2011 Great East Japan earthquake. The low and medium intensity levels correspond to a 20 and $70 \%$ of the original ground motion, respectively. The reference and high level correspond to a 100 and $200 \%$ of the original ground motion, respectively (15th WCEE Blind Test Challenge Preliminary Report 2012). The ground motions were applied in the longitudinal and transversal directions. The transversal direction (Fig. 2) is parallel to the beams ( $x$-axis) and the longitudinal direction (Fig. 2) parallel to the girders (z-axis). Figure 5a, b shows the ground motions used in the longitudinal and transversal directions for each intensity level. The ground motions were applied simultaneously to simulate test conditions. During the test experiment, each ground motion was applied after the frame suffered damage from previous test. Figure 6 shows the displacement time history results obtained from the analytical model developed in OpenSEES (OS) and the experimental results obtained during the test of the $3 \mathrm{D}$ reference frame for two selected intensities (Reference-REF and High) at node A (see Fig. 2). The analytical results are in good agreement with the experimental results.

\section{Results and discussion}

\section{Rotation limit states}

From the NLTHA, beam rotations were obtained for all the frames. In addition, beam and column rotation limits for different damage levels (IO, LS, CP) from the ASCE 41-06 standard were obtained. The values of ASCE 41-06 rotation limits for all beams of the 2D and 3D frames obtained were $0.005,0.01$ and 0.02 for IO, LS and CP, respectively. For the columns of the 3D frames, the ASCE rotation limits obtained were $0.005,0.01365$ and 0.0182 for IO, LS and $\mathrm{CP}$, respectively. These limits correspond to beams and columns with conforming transverse reinforcement. The rotation limits found from the ASCE standard were compared against the rotations obtained from the NLTHA. Figure 7 presents the maximum beam rotations as function of the peak ground acceleration (PGA) obtained from the 

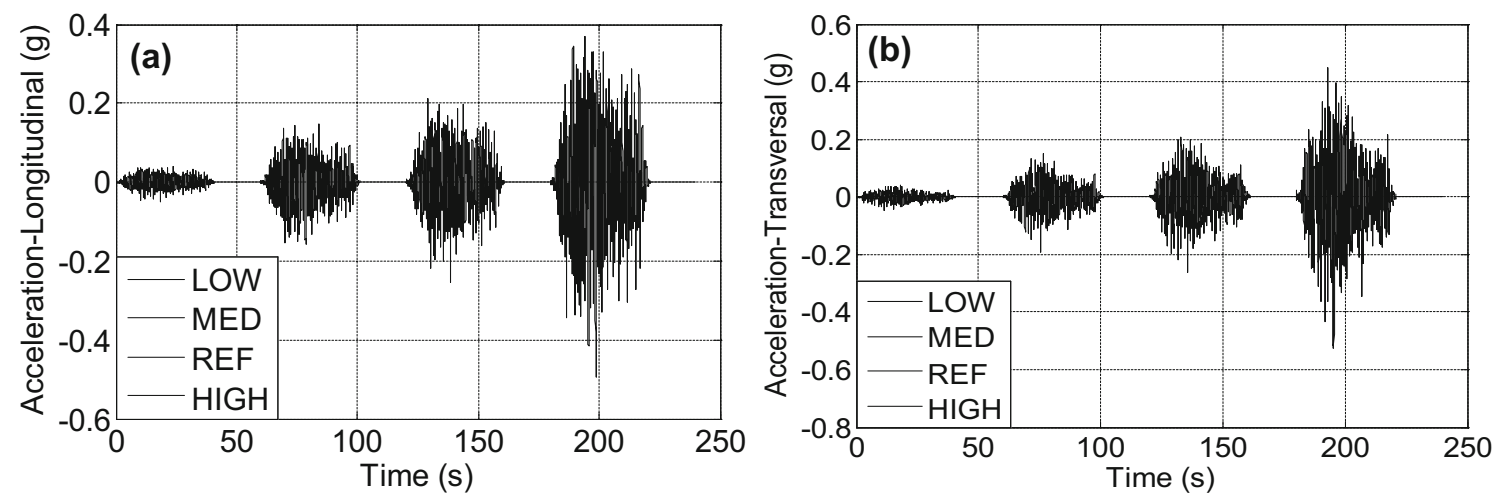

Fig. 5 Ground motion acceleration: a longitudinal ( $x$-axis), b transversal direction ( $z$-axis)

Fig. 6 Displacements for node $A$ in the 3D frame: analytical (OS) and experimental (challenge)
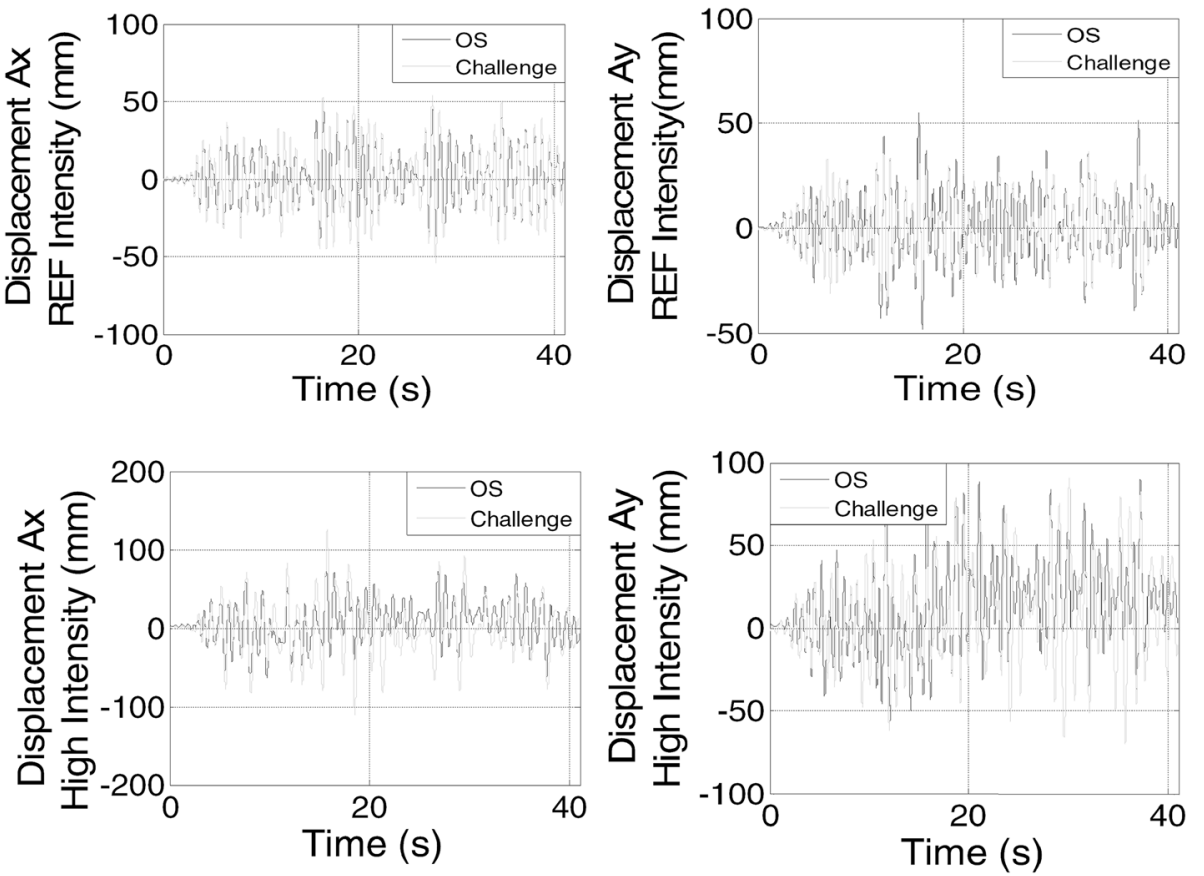

NLTHA using the 7 ground motions scaled from 0.1 to $1.5 \mathrm{~g}$ for frame $1(\mathrm{~L} / \mathrm{H}=7.5)$, frame $2(\mathrm{~L} / \mathrm{H}=9)$, frame 3 $(\mathrm{L} / \mathrm{H}=10)$, and frame $4(\mathrm{~L} / \mathrm{H}=12)$, respectively. For the sake of brevity, only the $2 \mathrm{D}$ frame results for beam reinforcement ratios of 1 and $2 \%$ were presented. Similar results were found for the frames with the other reinforcement steel ratios. The rotation limits for IO, LS and $\mathrm{CP}$ were also included in these figures and are represented as horizontal lines. In general, the rotations as function of the PGA show a linear tendency depending on the ground motion and peak ground acceleration. From Fig. 7, it can be deducted when certain ASCE limit state (IO, LS or CP) will be reached or exceeded when the horizontal line crosses approximately the average rotation line obtained from NLTHA. As example, the collapse prevention (CP) limit state (Fig. 7) is exceeded for frame 1 for PGA values higher than 0.9 to $1.1 \mathrm{~g}$ depending on the reinforcement steel ratio. For frame 4 the CP limit is exceeded for PGA values varying between 0.6 and $0.7 \mathrm{~g}$. The life safety (LS) limit is reached at average PGA values of 0.5 and $0.4 \mathrm{~g}$ for frames 1 and 4, respectively. The IO is exceeded at $0.3 \mathrm{~g}$ for frame 1 and $0.2 \mathrm{~g}$ for frame 4 .

Furthermore, Fig. 8 shows the variability of the rotations between span-to-depth ratios for selected ground motions (Chi-Chi and Kobe) and for selected steel reinforcement cases (1.0 and $2.0 \%$ ) to have a better perspective of the response of these frames. For the 2D frames the rotations decrease as the reinforcement ratio increases and increases as the span-to-depth ratio increases. Nonsymmetrical frames or with nonductile elements could present high nonlinearly in the rotations with respect to the PGA levels. However, the dependence on aspect ratios and reinforcing steel percentages is still expected for these cases. A better correlation of the limit states with these 

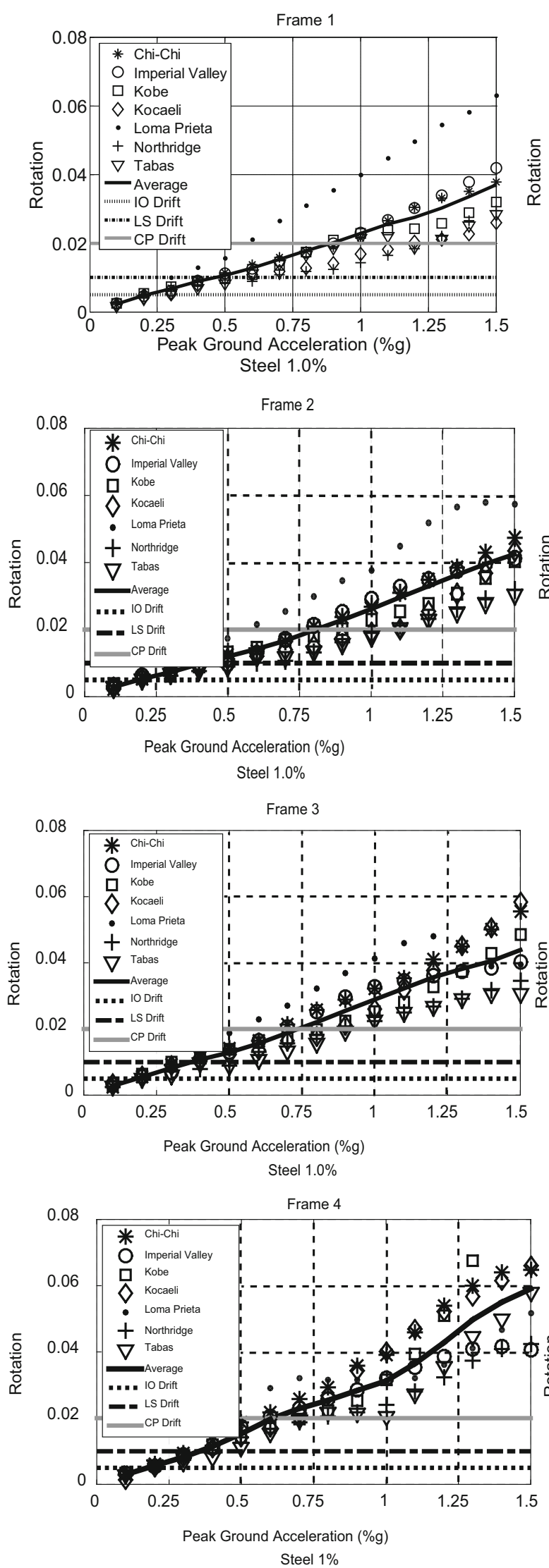

Steel $1 \%$

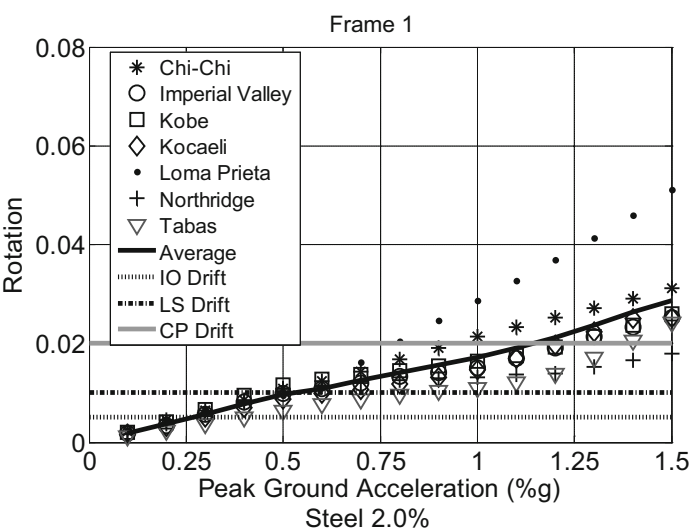

Frame 2

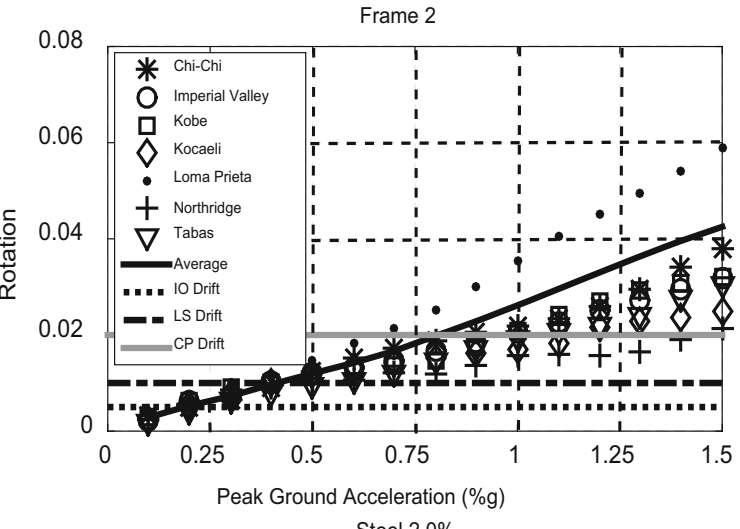

Steel $2.0 \%$

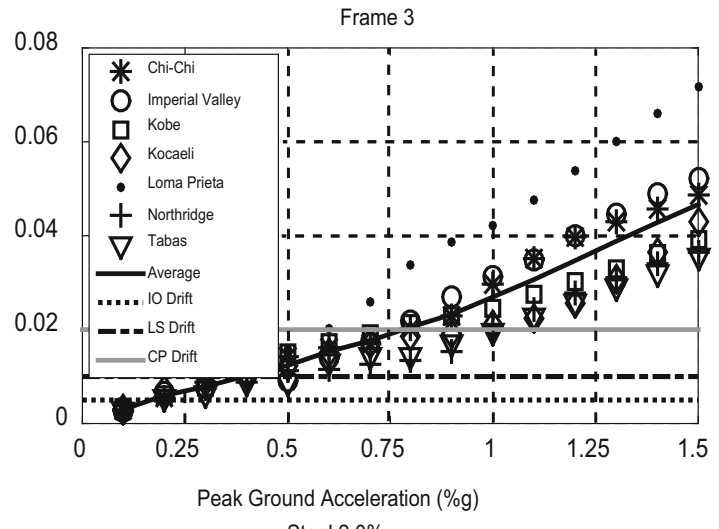

Steel $2.0 \%$

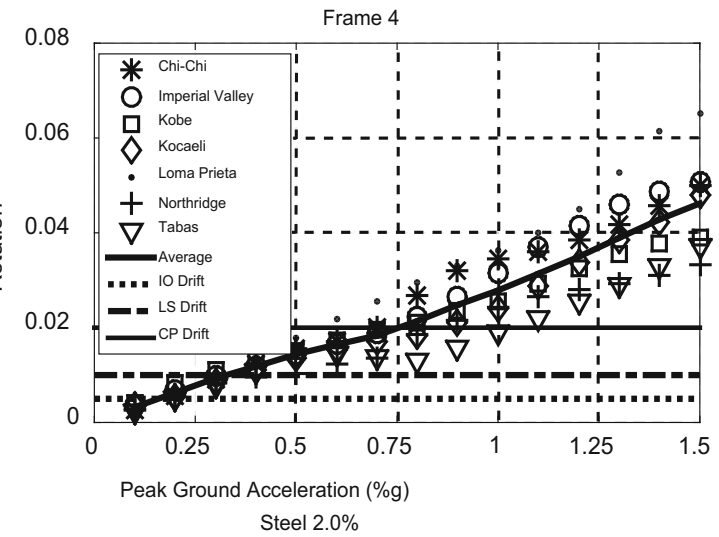

Fig. 7 Rotation vs. PGA frames 1-4 with reinforcing steel ratios of 1 and 2\% 
Fig. 8 Rotations vs PGA for selected ground motions
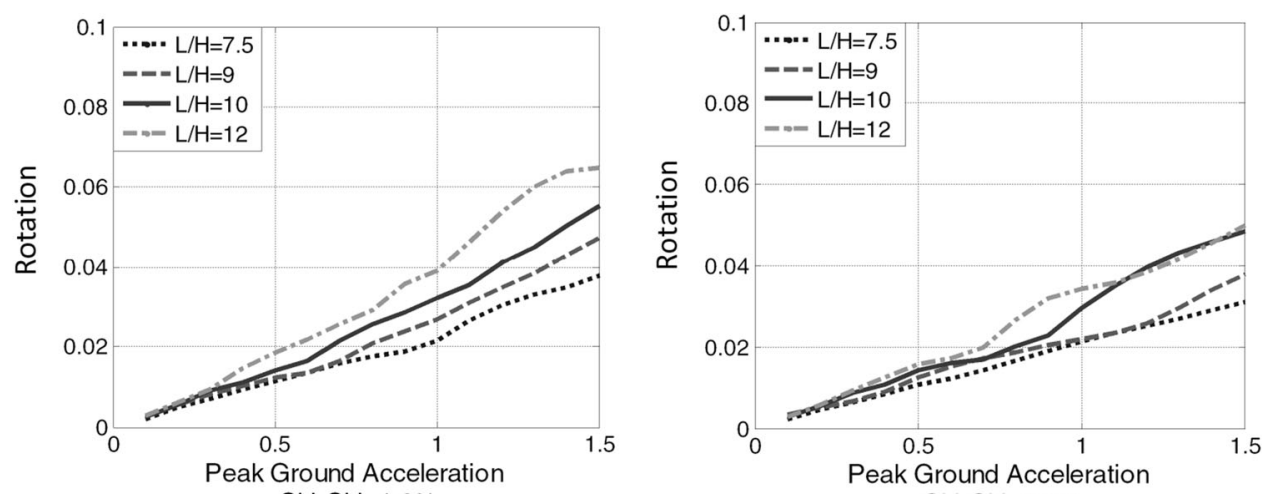

Chi-Chi $-1.0 \%$
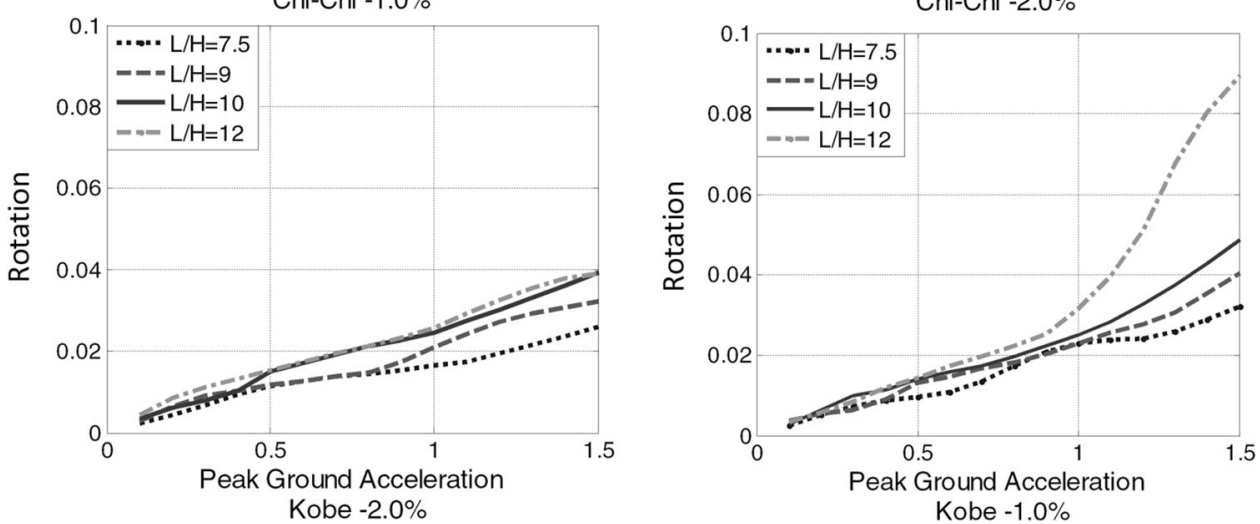
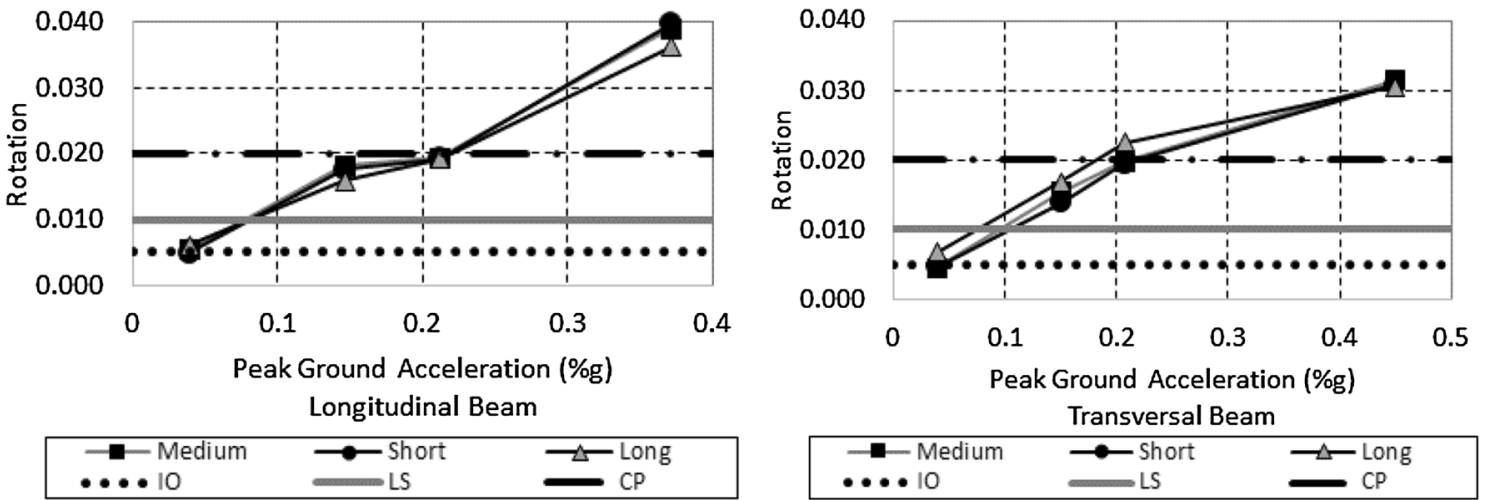

Fig. 9 Rotation vs. PGA-3D frames

parameters needs further investigation for more complex frame cases.

Figure 9 shows the rotations in each direction (longitudinal and transversal) obtained for 3D frames as function of the 4 levels (low, medium, reference, high) of PGA used in the analyses. The three frames are denoted as medium (reference), short and long indicating the span-to-depth ratio value. For the 3D frames (Fig. 9), the rotations for the low PGA level are very similar to the IO rotation limits established by the ASCE 41-06. Also, the rotation for the reference PGA, in both directions, exceeded the LS limit, but is under the CP limit state for two frame cases. The rotations for the high PGA level exceeded the CP limit state. From these results (2D and 3D frames), it can be deducted that the ASCE standard limits (IO, LS, CP) based on constant rotations are not necessarily appropriate if the goal is to ensure constant damage for the same type of frame structure since rotations are dependent on the spanto-depth ratios and seismic level demands. Although, ASCE 41-06 rotation limits depend on the level of reinforcement ratio and shear strengths, it would be more appropriate to define these limits with detailed expressions that include the span-to-depth ratio, reinforcement steel and section properties to predict much better the level of seismic performance desired for the structure. For the 3D frames, the variability in rotations is less evident when 
compared to the 2D frames. However, PGA levels for the 3D frames are lower than the PGA levels that were subjected the $2 \mathrm{D}$ frames. The variability in the rotations increases for higher levels of PGA.

\section{Strain limit states}

From the NLTHA, the concrete and steel strains in the beams of the 2D frames and columns of the 3D frames were obtained where the maximum rotations occurred for all cases. The concrete and steel strains were found at the location of the extreme compression and tension fibers, respectively. Strains at the columns of the 3D frames were used because this frame follows a weak column-strong beam mechanism. The ASCE IO, LS and CP rotation limit states were used to interpolate the strains values corresponding to these limits from the NLTHA results. Figure 10 presents the steel strains as function of the PGA values for frames 1-4 with 1 and $2 \%$ of reinforcing steel, respectively. Again, similar results were obtained for the other reinforcing steel ratios considered in this study. Figure 11 shows the concrete compression strains as function of the PGA values for frames 1-4 with 1 and $2 \%$ of reinforcing steel, respectively. In these figures, the lines for the strain limits found from the interpolation of the ASCE rotation limit states are also included. The steel strain limits show a linear tendency; meanwhile, concrete strain limits show a less linear tendency in function of span-to-depth ratios. Comparable with the rotation limits, it can be deducted from these figures when a strain limit is going to be reached or exceeded. As example, it can be noted from Figs. 10 and 11 that strains for CP limit state are exceeded at 0.9 and $0.6 \mathrm{~g}$ for frame 1 and frame 4, respectively. The life safety (LS) limits are reached at average PGA values of $0.4 \mathrm{~g}$ for frames 1 and 4 . The IO is exceeded at an average PGA of $0.2 \mathrm{~g}$ for frames 1 and 4 .

Tables 1, 2, 3 and 4 show the steel and concrete strains found at LS and CP rotation limit states for frames 1 and 4 with 1 and $2 \%$ of reinforcement steel including the PGA level in which the limit was reached for each earthquake case. For frame 1, the LS limit state steel strains varied from 0.013 to 0.024 and 0.0074 to 0.0149 for 1 and $2 \%$ of reinforcing steel, respectively. For frame 4 , the LS limit state steel strains varied from 0.0117 to 0.0325 and 0.0059 to 0.0242 for 1 and $2 \%$ of reinforcing steel, respectively. These values occurred at different PGA values depending on the earthquake case with the variability increasing as the rotation limit increases. For frame 1, the CP limit state steel strains varied from 0.030 to 0.0412 and 0.0198 to 0.0307 for 1 and $2 \%$ of reinforcing steel, respectively. For frame 4, the CP limit state steel strains varied from 0.0234 to 0.0459 and 0.0123 to 0.0337 for 1 and $2 \%$ of reinforcing steel, respectively. For frame 4, the values of PGA at which each limit was reached show less variation. For frame 1, the concrete compression strains for the LS limit state varied from 0.0004 to 0.0019 depending on the reinforcement steel ratio. For frame 4, the CP limit concrete compression strains fluctuated between 0.0008 and 0.0034 depending on the reinforcement steel ratio.

Tables 5 and 6 show the average steel and concrete strains obtained for all frame cases. The serviceability limit state is usually defined at a concrete compression strain of 0.004 or steel tension strain of 0.015 (whichever occurs first) as suggested by Priestley et al. (2007). The damage control limit state is defined as a concrete compression strain of 0.018 or steel tension strain of 0.060 , whichever occurs first in the section. The LS and CP limit states are equivalent to the serviceability and damage control presented by Priestley et al. (2007). Comparing the average strain values (Tables 5, 6) obtained in this study with the typical values for serviceability and damage control, it can be noted that the LS limit average strains are similar, but the CP limit state is more conservative. From these results (especially the steel strain limits), it can be also observed that the strains are almost independent of the ground motion history (Tables 1, 2, 3, 4). This has been proven by some researchers (Vidot-Vega and Kowalsky 2011; Goodnight et al. 2013).

In addition, steel and concrete strains were found for each PGA level (low, medium, reference and high) for the reference 3D frame. These results are shown in Fig. 12. Similar to the 2D frames, with the ASCE 41-06 rotation limit states (IO, LS, and $\mathrm{CP}$ ) an interpolation was performed to determine the steel and concrete compression strains at these limits (horizontal lines in Fig. 12). For the columns, all cases exceed the IO limit. The CP limit state was exceeded for the reference and high ground motion intensities.

\section{Seismic hysteretic energy limit states}

The purpose of studying the seismic hysteretic energy in relation to the limit states is to try to identify if this parameter can be used as performance indicator like the drifts and strains. For the 2D frames, the seismic hysteretic energy was obtained using the area under the moment vs. rotation curves. The moment and rotations at the beams were obtained from the nonlinear time history analyses. The hysteretic energy was calculated at each beam plastic hinge. The total hysteretic energy dissipated in one frame story is the sum of the energy calculated at each hinge. The energy was obtained as function of the PGA and/or ductility as shown in Fig. 13 for the seven ground motions used in the analyses (EQ. 1-EQ. 7). This figure shows only the results for the cases with reinforcement steel ratios of 1 and $2 \%$ for sake of brevity. Similar results were found for 

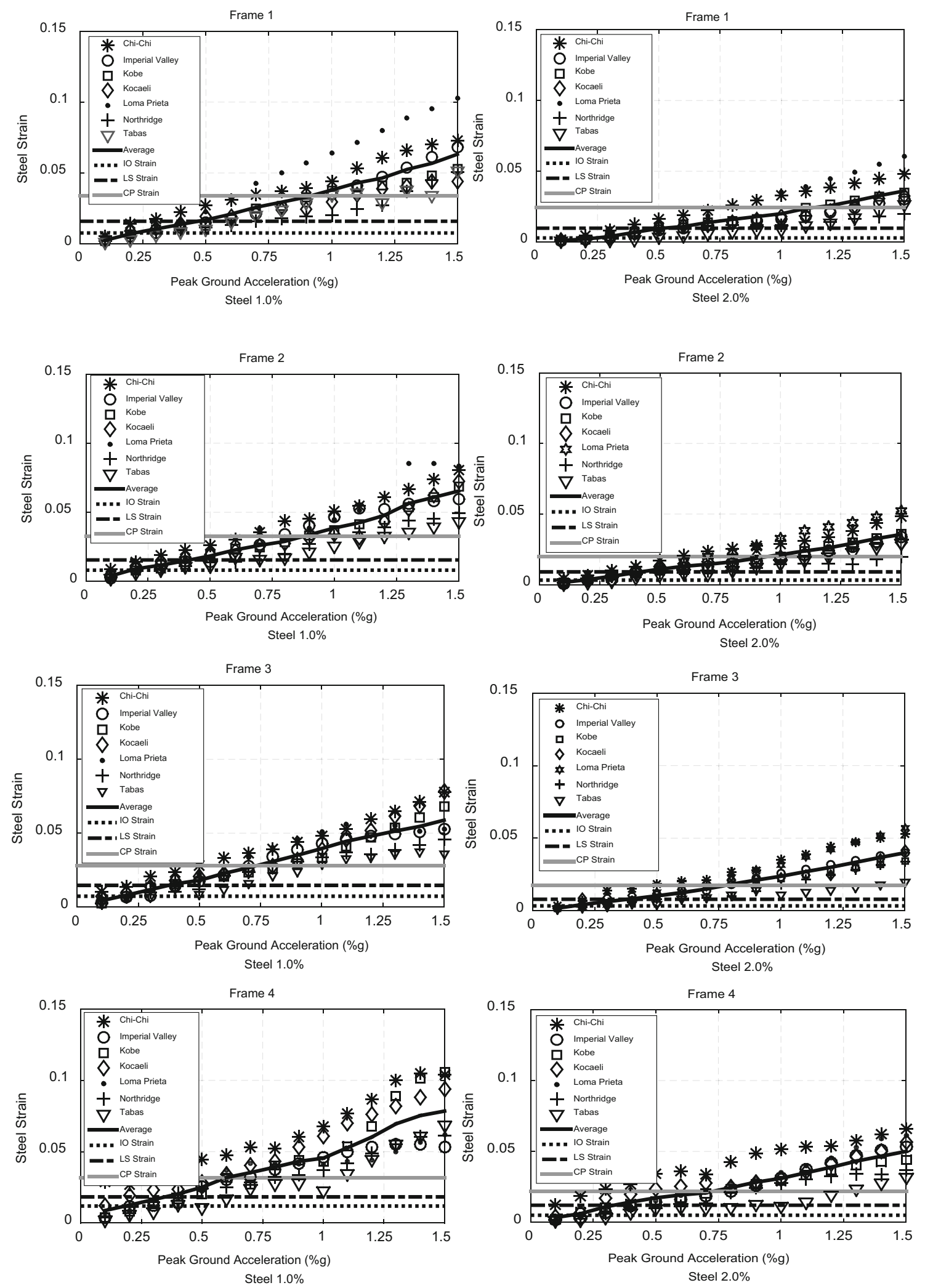

Fig. 10 Steel strain vs. PGA frames 1-4 for reinforcing steel ratios of 1 and $2 \%$ 

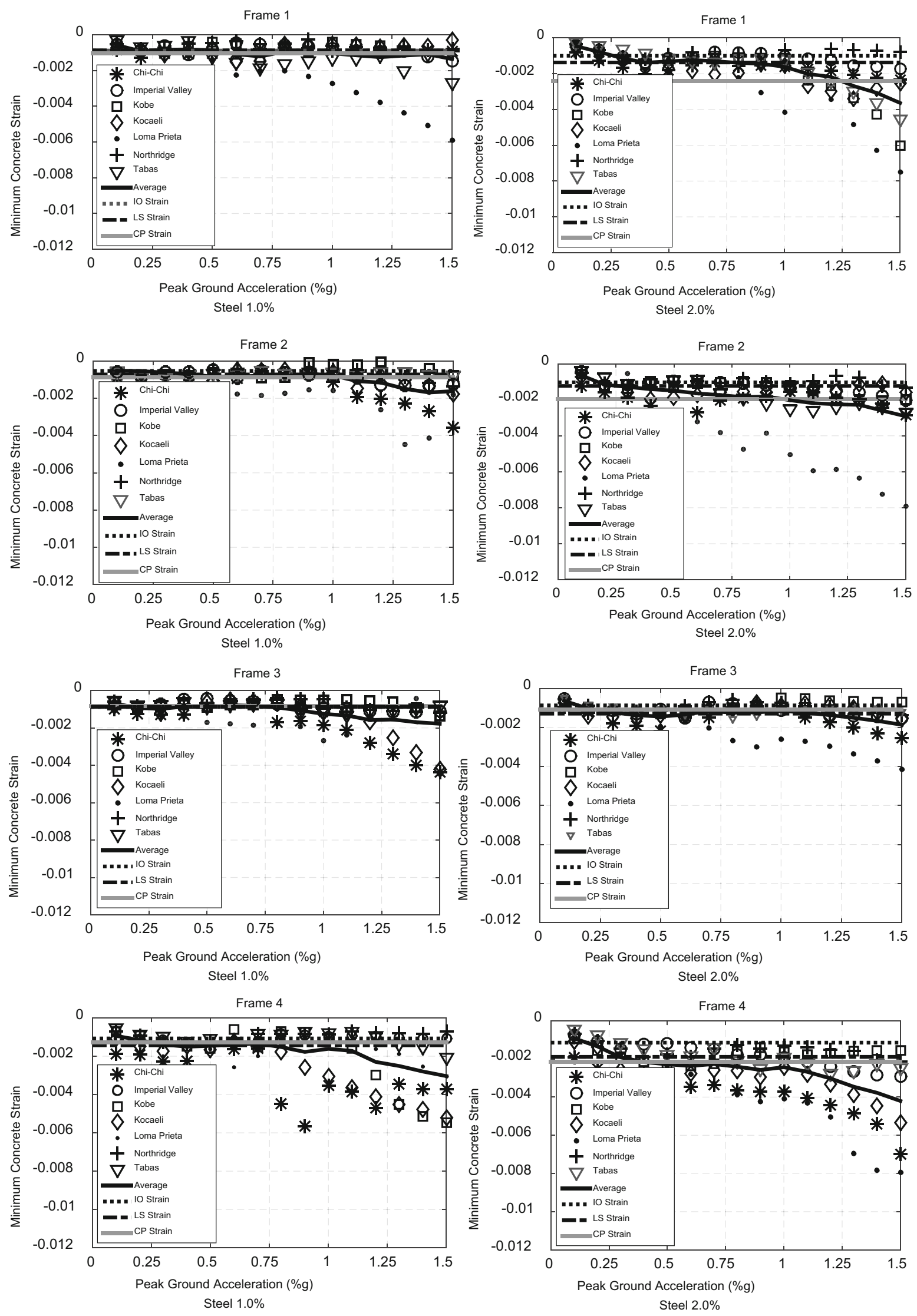

Fig. 11 Concrete strain vs. PGA frames 1-4 for reinforcing steel ratios of 1 and $2 \%$ 
Table 1 Steel strains at selected limit states for frame 1

\begin{tabular}{|c|c|c|c|c|c|c|c|c|}
\hline \multicolumn{9}{|l|}{ Frame 1 -steel strain } \\
\hline \multirow[t]{2}{*}{ Earthquake } & \multicolumn{4}{|c|}{ Reinforcing steel $1.0 \%$} & \multicolumn{4}{|c|}{ Reinforcing steel $2.0 \%$} \\
\hline & $\mathrm{PGA}_{\mathrm{LS}}$ & LS & $\mathrm{PGA}_{\mathrm{CP}}$ & $\mathrm{CP}$ & $\mathrm{PGA}_{\mathrm{LS}}$ & LS & $\mathrm{PGA}_{\mathrm{CP}}$ & $\mathrm{CP}$ \\
\hline Chi-Chi & 0.50 & 0.0242 & 1.00 & 0.0412 & 0.50 & 0.0149 & 1.00 & 0.0307 \\
\hline Imperial Valley & 0.50 & 0.0130 & 1.00 & 0.0302 & 0.60 & 0.0086 & 1.30 & 0.0222 \\
\hline Kobe & 0.60 & 0.0142 & 0.90 & 0.0312 & 0.50 & 0.0082 & 1.30 & 0.0273 \\
\hline Kocaeli & 0.60 & 0.0194 & 1.20 & 0.0382 & 0.70 & 0.0116 & 1.30 & 0.0223 \\
\hline Loma Prieta & 0.40 & 0.0127 & 0.60 & 0.0307 & 0.60 & 0.0083 & 0.80 & 0.0237 \\
\hline Northridge & 0.70 & 0.0150 & 1.30 & 0.0316 & 0.50 & 0.0089 & 0.00 & 0.0198 \\
\hline Tabas & 0.60 & 0.0135 & 1.00 & 0.0334 & 0.90 & 0.0074 & 1.40 & 0.0208 \\
\hline Max & 0.70 & 0.0242 & 1.30 & 0.0412 & 0.90 & 0.0149 & 1.40 & 0.0307 \\
\hline Min & 0.40 & 0.0127 & 0.60 & 0.0302 & 0.50 & 0.0074 & 0.00 & 0.0198 \\
\hline Standard deviation & 0.10 & 0.0043 & 0.22 & 0.0042 & 0.15 & 0.0026 & 0.49 & 0.0039 \\
\hline
\end{tabular}

Table 2 Steel strains at selected limit states for frame 4

\begin{tabular}{|c|c|c|c|c|c|c|c|c|}
\hline \multicolumn{9}{|l|}{ Frame 4-steel strain } \\
\hline \multirow[t]{2}{*}{ Earthquake } & \multicolumn{4}{|c|}{ Reinforcing steel $1.0 \%$} & \multicolumn{4}{|c|}{ Reinforcing steel $2.0 \%$} \\
\hline & $\mathrm{PGA}_{\mathrm{LS}}$ & LS & $\mathrm{PGA}_{\mathrm{CP}}$ & $\mathrm{CP}$ & $\mathrm{PGA}_{\mathrm{LS}}$ & LS & $\mathrm{PGA}_{\mathrm{CP}}$ & $\mathrm{CP}$ \\
\hline Chi-Chi & 0.40 & 0.0325 & 0.60 & 0.0459 & 0.40 & 0.0242 & 0.80 & 0.0337 \\
\hline Imperial Valley & 0.40 & 0.0132 & 0.60 & 0.0296 & 0.40 & 0.0075 & 0.80 & 0.0193 \\
\hline Kobe & 0.40 & 0.0153 & 0.80 & 0.0282 & 0.30 & 0.0091 & 0.80 & 0.0212 \\
\hline Kocaeli & 0.40 & 0.0236 & 0.70 & 0.0382 & 0.40 & 0.0185 & 0.90 & 0.0270 \\
\hline Loma Prieta & 0.40 & 0.0139 & 0.60 & 0.0255 & 0.30 & 0.0087 & 0.60 & 0.0171 \\
\hline Northridge & 0.40 & 0.0181 & 0.80 & 0.0310 & 0.50 & 0.0105 & 0.90 & 0.0227 \\
\hline Tabas & 0.50 & 0.0117 & 0.80 & 0.0234 & 0.40 & 0.0059 & 1.10 & 0.0123 \\
\hline $\operatorname{Max}$ & 0.50 & 0.0325 & 0.80 & 0.0459 & 0.50 & 0.0242 & 1.10 & 0.0337 \\
\hline Min & 0.40 & 0.0117 & 0.60 & 0.0234 & 0.30 & 0.0059 & 0.60 & 0.0123 \\
\hline Standard deviation & 0.04 & 0.0074 & 0.10 & 0.0079 & 0.07 & 0.0067 & 0.15 & 0.0069 \\
\hline
\end{tabular}

Table 3 Concrete strains at selected limit states for frame 1

\begin{tabular}{|c|c|c|c|c|c|c|c|c|}
\hline \multicolumn{9}{|c|}{ Frame 1 -minimum concrete strain } \\
\hline \multirow[t]{2}{*}{ Earthquake } & \multicolumn{4}{|c|}{ Reinforcing steel $1.0 \%$} & \multicolumn{4}{|c|}{ Reinforcing steel $2.0 \%$} \\
\hline & $\mathrm{PGA}_{\mathrm{LS}}$ & LS & $\mathrm{PGA}_{\mathrm{CP}}$ & $\mathrm{CP}$ & $\mathrm{PGA}_{\mathrm{LS}}$ & LS & $\mathrm{PGA}_{\mathrm{CP}}$ & $\mathrm{CP}$ \\
\hline Chi-Chi & 0.50 & -0.0011 & 1.00 & -0.0008 & 0.50 & -0.0019 & 1.00 & -0.0016 \\
\hline Imperial Valley & 0.50 & -0.0010 & 1.00 & -0.0007 & 0.60 & -0.0011 & 1.30 & -0.0013 \\
\hline Kobe & 0.60 & -0.0004 & 0.90 & -0.0008 & 0.50 & -0.0014 & 1.30 & -0.0029 \\
\hline Kocaeli & 0.60 & -0.0009 & 1.20 & -0.0007 & 0.70 & -0.0019 & 1.30 & -0.0030 \\
\hline Loma Prieta & 0.40 & -0.0008 & 0.60 & -0.0021 & 0.60 & -0.0011 & 0.80 & -0.0022 \\
\hline Northridge & 0.70 & -0.0005 & 1.30 & -0.0007 & 0.50 & -0.0010 & 0.00 & -0.0008 \\
\hline Tabas & 0.60 & -0.0014 & 1.00 & -0.0016 & 0.90 & -0.0012 & 1.40 & -0.0035 \\
\hline Max & 0.70 & -0.0004 & 1.30 & -0.0007 & 0.90 & -0.0010 & 1.40 & -0.0008 \\
\hline Min & 0.40 & -0.0014 & 0.60 & -0.0021 & 0.50 & -0.0019 & 0.00 & -0.0035 \\
\hline Standard deviation & 0.10 & 0.0003 & 0.22 & 0.0006 & 0.15 & 0.0004 & 0.49 & 0.0010 \\
\hline
\end{tabular}


Table 4 Concrete strains at selected limit states for frame 4

Table 5 Average steel strains at different limit states for all frames

Table 6 Average concrete strains at different limit states for all frames

\begin{tabular}{|c|c|c|c|c|c|c|c|c|}
\hline \multicolumn{9}{|c|}{ Frame 4 -minimum concrete strain } \\
\hline \multirow[t]{2}{*}{ Earthquake } & \multicolumn{4}{|c|}{ Reinforcing steel $1.0 \%$} & \multicolumn{4}{|c|}{ Reinforcing steel $2.0 \%$} \\
\hline & $\mathrm{PGA}_{\mathrm{LS}}$ & LS & $\mathrm{PGA}_{\mathrm{CP}}$ & $\mathrm{CP}$ & $\mathrm{PGA}_{\mathrm{LS}}$ & LS & $\mathrm{PGA}_{\mathrm{CP}}$ & $\mathrm{CP}$ \\
\hline Chi-Chi & 0.40 & -0.0023 & 0.60 & -0.0014 & 0.40 & -0.0032 & 0.80 & -0.0034 \\
\hline Imperial Valley & 0.40 & -0.0012 & 0.60 & -0.0014 & 0.40 & -0.0015 & 0.80 & -0.0016 \\
\hline Kobe & 0.40 & -0.0014 & 0.80 & -0.0014 & 0.30 & -0.0017 & 0.80 & -0.0021 \\
\hline Kocaeli & 0.40 & -0.0016 & 0.70 & -0.0013 & 0.40 & -0.0027 & 0.90 & -0.0028 \\
\hline Loma Prieta & 0.40 & -0.0012 & 0.60 & -0.0018 & 0.30 & -0.0017 & 0.60 & -0.0026 \\
\hline Northridge & 0.40 & -0.0013 & 0.80 & -0.0008 & 0.50 & -0.0019 & 0.90 & -0.0014 \\
\hline Tabas & 0.50 & -0.0011 & 0.80 & -0.0008 & 0.40 & -0.0014 & 1.10 & -0.0020 \\
\hline Max & 0.50 & -0.0011 & 0.80 & -0.0008 & 0.50 & -0.0014 & 1.10 & -0.0014 \\
\hline Min & 0.40 & -0.0023 & 0.60 & -0.0018 & 0.30 & -0.0032 & 0.60 & -0.0034 \\
\hline Standard deviation & 0.04 & 0.0004 & 0.10 & 0.0004 & 0.07 & 0.0007 & 0.15 & 0.0007 \\
\hline
\end{tabular}

\begin{tabular}{|c|c|c|c|c|c|c|c|c|}
\hline \multirow[t]{3}{*}{$\%$ Steel } & \multicolumn{8}{|c|}{ Steel strain limits } \\
\hline & \multicolumn{2}{|c|}{ Frame 1} & \multicolumn{2}{|c|}{ Frame 2} & \multicolumn{2}{|c|}{ Frame 3} & \multicolumn{2}{|c|}{ Frame 4} \\
\hline & LS & $\mathrm{CP}$ & LS & $\mathrm{CP}$ & LS & $\mathrm{CP}$ & LS & $\mathrm{CP}$ \\
\hline 0.85 & 0.0179 & 0.0385 & 0.0149 & 0.0308 & 0.0158 & 0.0298 & & \\
\hline 1 & 0.0160 & 0.0338 & 0.0155 & 0.0328 & 0.0147 & 0.0283 & 0.0183 & 0.0317 \\
\hline 1.5 & 0.0088 & 0.0198 & 0.0126 & 0.0254 & 0.0104 & 0.0232 & 0.0157 & 0.0273 \\
\hline 2 & 0.0097 & 0.0238 & 0.0090 & 0.0199 & 0.0079 & 0.0177 & 0.0121 & 0.0219 \\
\hline 2.5 & & & & & & & 0.0037 & 0.0201 \\
\hline
\end{tabular}
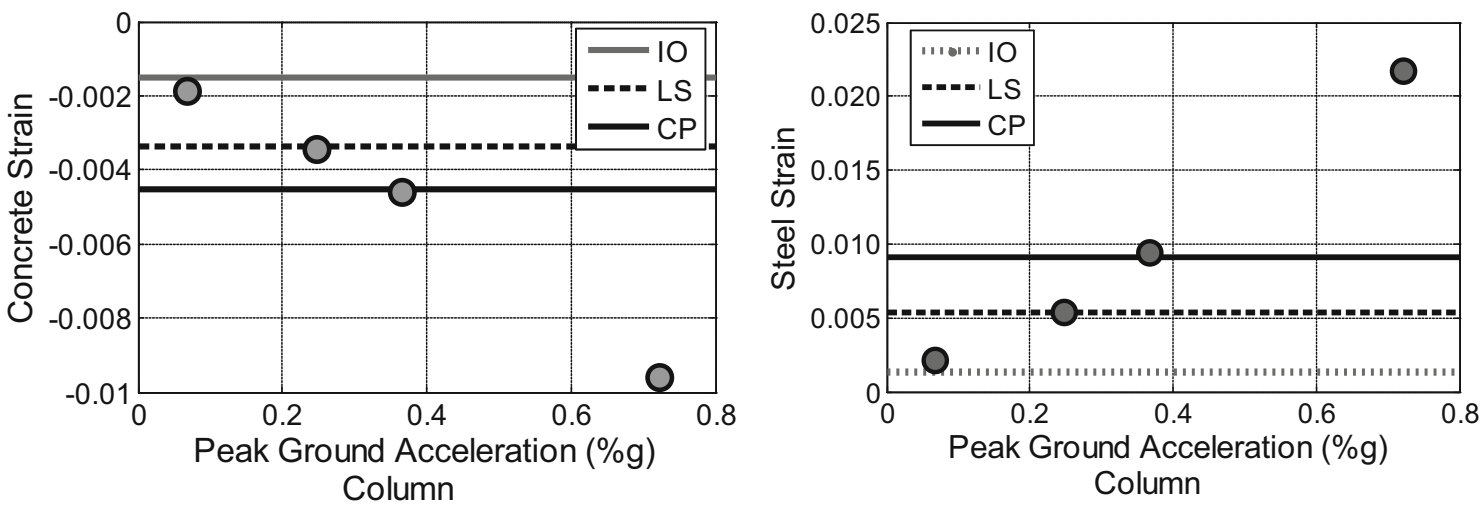

Fig. 12 Strain vs. PGA-3D reference (medium) frame 

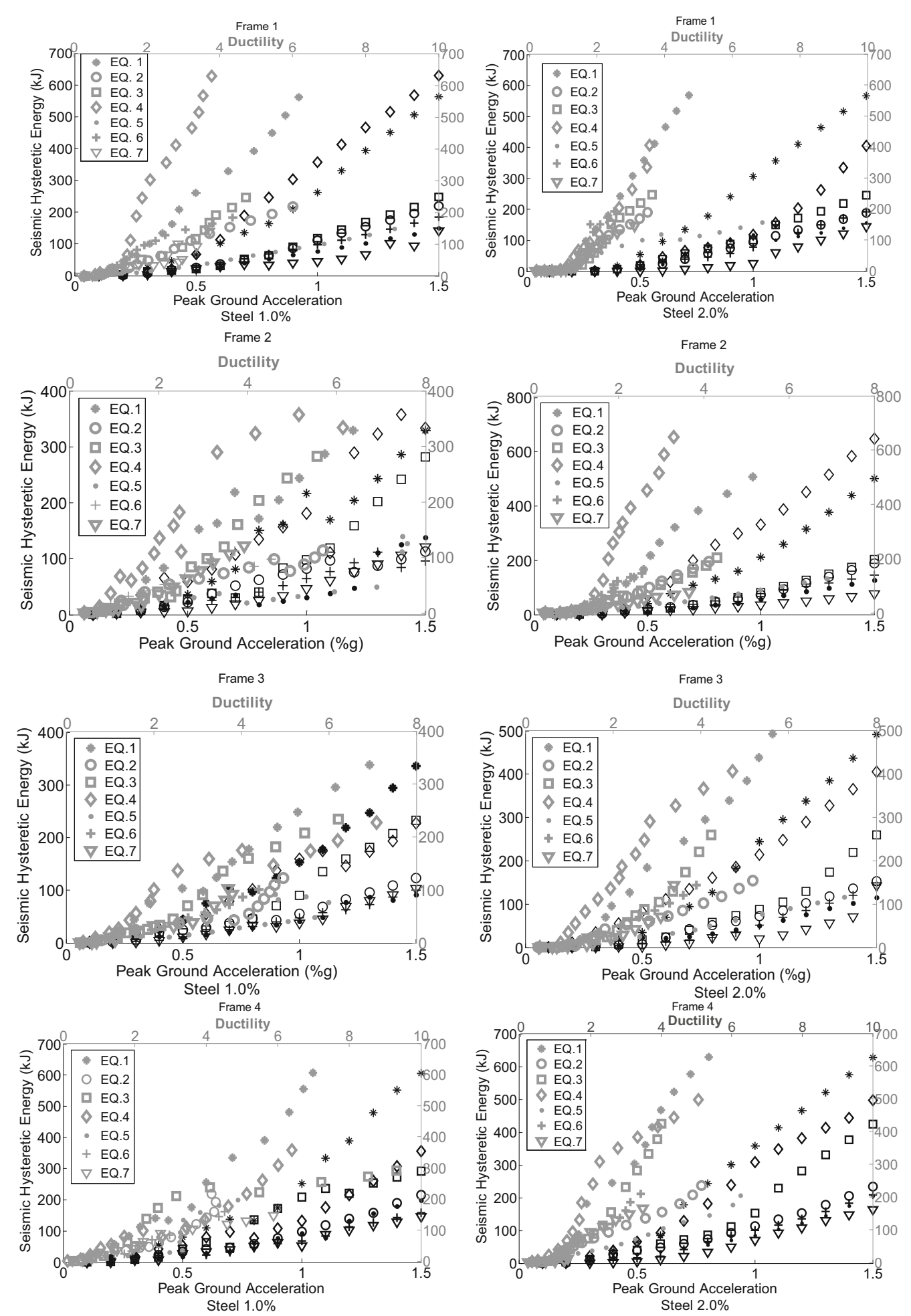

EQ. 1 - Chi-Chi; EQ. 2 - Imperial Valley; EQ. 3 - Kobe; EQ.4 - Kocaeli; EQ.5 - Loma Prieta; EQ. 6 - Northridge; EQ 7 - Tabas

Fig. 13 Seismic hysteretic energy vs. PGA/ductility frames $1-4-1$ and $2 \%$ steel ratios 
Table 7 Seismic hysteretic energy at LS and CP limit states for all frames with 1 and $2 \%$

\begin{tabular}{|c|c|c|c|c|c|c|c|c|c|}
\hline \multicolumn{2}{|l|}{ Steel \% } & \multicolumn{4}{|l|}{$1 \%$} & \multicolumn{4}{|l|}{$2 \%$} \\
\hline Frame & Statistical & $\mathrm{PGA}_{\mathrm{LS}}$ & $\mathrm{LS}$ & $\mathrm{PGA}_{\mathrm{CP}}$ & $\mathrm{CP}$ & $\mathrm{PGA}_{L S}$ & LS & $\mathrm{PGA}_{\mathrm{CP}}$ & $\mathrm{CP}$ \\
\hline \multirow[t]{4}{*}{ Frame 1} & Average & 0.56 & 36.87 & 1.00 & 157.90 & 0.61 & 25.11 & 1.23 & 169.92 \\
\hline & Max & 0.70 & 76.66 & 1.30 & 456.16 & 0.90 & 50.78 & 1.50 & 267.53 \\
\hline & Min & 0.40 & 9.75 & 0.60 & 26.04 & 0.50 & 11.00 & 0.80 & 79.10 \\
\hline & Standard deviation & 0.09 & 22.93 & 0.21 & 146.07 & 0.14 & 15.08 & 0.22 & 62.89 \\
\hline \multirow[t]{4}{*}{ Frame 2} & Average & 0.49 & 22.47 & 0.91 & 79.05 & 0.47 & 17.24 & 1.06 & 131.81 \\
\hline & Max & 0.60 & 62.61 & 1.10 & 135.04 & 0.60 & 25.09 & 1.50 & 421.44 \\
\hline & Min & 0.40 & 7.39 & 0.60 & 26.37 & 0.40 & 6.75 & 0.70 & 24.22 \\
\hline & Standard deviation & 0.08 & 18.59 & 0.18 & 38.63 & 0.09 & 6.69 & 0.23 & 136.12 \\
\hline \multirow[t]{4}{*}{ Frame 3} & Average & 0.46 & 14.57 & 0.81 & 55.43 & 0.44 & 13.19 & 0.87 & 73.34 \\
\hline & Max & 0.60 & 25.45 & 1.00 & 126.78 & 0.60 & 50.74 & 1.10 & 199.80 \\
\hline & Min & 0.40 & 8.21 & 0.60 & 12.24 & 0.40 & 2.62 & 0.60 & 21.07 \\
\hline & Standard deviation & 0.09 & 6.05 & 0.14 & 40.31 & 0.07 & 17.20 & 0.16 & 65.80 \\
\hline \multirow[t]{4}{*}{ Frame 4} & Average & 0.41 & 20.49 & 0.70 & 56.09 & 0.39 & 13.93 & 0.84 & 103.12 \\
\hline & Max & 0.50 & 35.07 & 0.80 & 93.68 & 0.50 & 30.50 & 1.10 & 216.72 \\
\hline & Min & 0.40 & 8.89 & 0.60 & 20.41 & 0.30 & 2.15 & 0.60 & 31.58 \\
\hline & Standard deviation & 0.03 & 8.93 & 0.09 & 27.14 & 0.06 & 8.99 & 0.14 & 67.74 \\
\hline
\end{tabular}

the other reinforcing steel ratios used in this study. For all the 2D frames the higher seismic hysteretic energies were obtained for the EQ. 1 (Chi-Chi) and EQ. 4 (Kocaeli) ground motions. These ground motions are the ones with the larger Arias Intensity (AI), Cumulative Absolute Velocity (CAV) and Specific Energy Densities (SED). The $\mathrm{AI}$ is a measure of the strength of a ground motion (EPRI NP-5930 1988) and was calculated as the integral of the square of the acceleration time histories (Arias 1970). The CAV represents the possible onset of structural damage and was calculated as the area under the absolute acceleration time histories (EPRI NP-5930 1988). The SED is defined as the sum of the square of the velocity time histories (EPRI NP-5930 1988).

From these figures, the strong variability of the seismic hysteretic energies with the ground motions can be noted. The ground motions have different characteristics which have a strong influence in the seismic hysteretic energy. These results have been confirmed by some researches (Park et al. 1987; Bommer and Martinez-Pereira 2000; Wong 2002; Kazantzi 2012). The hysteretic energy has been recognized by several researchers as a potentially useful seismic performance indicator (e.g., Park et al. 1987; Bojorquez et al. 2011). However, its strong dependence on the seismic input presents a drawback to be used as a parameter for the definition of code limit states.

From the NLTHA results, the seismic hysteretic energy was obtained at beams on the story where the maximum drifts were recorded. For this reason, seismic hysteretic energies were obtained as function of maximum drifts or rotations for each PGA level. Then, values of hysteretic energies for the corresponding ASCE 41-06 rotation limit states were interpolated at each corresponding rotation value. Table 7 presents maximum, minimum and average seismic energy values at the LS and CP limit states obtained with the 7 ground motions considered in this paper for all frames with 1.0 and $2 \%$ of steel reinforcement ratio. From this table, the variability of the energy values between each limit state and ground motion as indicated by the standard deviation obtained can be observed.

\section{Conclusions}

This paper presented the results from NLTHA of RC moment resisting frames and evaluation of material strains, rotations and seismic hysteretic energies at different damage levels established by the ASCE 41-06 standard. The primary conclusions are the following:

The dependence of the seismic hysteretic energy on the characteristics of the ground motion was confirmed. Although this energy is a useful parameter to describe in some sense the seismic performance of a structure, the use of this parameter to define damage limit states to be used in seismic rehabilitation codes can be challenging and needs more work to be done.

Limit-state rotations varied between each span-to-depth ratio and longitudinal steel reinforcement ratio. This implies that better expressions are needed to obtain limit state rotations in function of these parameters.

The inclusion of strains in the definition of limit states to be used in rehabilitation standards could be beneficial 
since in general the strains allow a better indication of the damage across the structure than the drift or rotations alone. However, in order to include strains to define limit states in a more detailed fashion more experimental tests are necessary.

Acknowledgements The research described in this paper was financially supported by University of Puerto Rico at Mayaguez. The support is greatly appreciated.

Open Access This article is distributed under the terms of the Creative Commons Attribution 4.0 International License (http://crea tivecommons.org/licenses/by/4.0/), which permits unrestricted use, distribution, and reproduction in any medium, provided you give appropriate credit to the original author(s) and the source, provide a link to the Creative Commons license, and indicate if changes were made.

\section{References}

Arias A (1970) A Measure of Earthquake Intensity. In: Hansen RJ (ed) Seismic Design for Nuclear Power Plants. MIT Press, Cambridge, pp 438-483

ASCE 41-06 (2007) Seismic rehabilitation of existing building. American Society of Civil Engineers, ASCE, Reston

ASCE 7-05 (2006) Minimum design loads for buildings and other structures. American Society of Civil Engineers, ASCE, Reston

Bojorquez E, Teran-Gilmore A, Ruiz SE, Reyes-Salazar A (2011) Evaluation of structural reliability of steel frames: interstory drift versus plastic hysteretic energy. Earthq Spectra 27(3):661-682

Bommer JJ, Martinez-Pereira A (2000) Strong motion parameters: definition, usefulness and predictability. Proc. of the 10th World Conference on Earthquake Engineering, Auckland, 2000; Paper No. 206

Chang G, Mander J (1994) Seismic energy based fatigue damage analysis of bridge columns: part I-evaluation of seismic capacity. NCEER Technical Report 94-0006

EPRI NP-5930 (1988) A Criterion for Determining Exceedance of the Operating Basis Earthquake, Electric Power Research Institute,
Research Project 2848-16. Jack R. Benjamin and Associates, Inc., Mountain View

Goodnight J, Kowalsky M, Nau J (2013) The effect of load history on performance limit states of circular bridge columns (Special Edition). J Bridge Eng 18:1383-1396

Karsan I, Jirsa J (1969) Behavior of concrete under compressive loadings. ASCE J Struct Div 95(12):2543-2563

Kazantzi AK, Vamvatsikos D (2012) A study on the correlation between dissipated hysteretic energy and seismic performance. Proc. of the 15th World Conference on Earthquake Engineering, Lisbon, 2012

Kent DC, Park R (1971) Flexural members with confined concrete. ASCE J Struct Eng 97(7):1969-1990

Mander JP, Priestley MJN, Park R (1988) Theoretical stress-strain model for confined concrete. ASCE J Struct Eng 114(8):1804-1826

McKenna F, Fenves G, Filippou F, Mazzoni S, Scott M, Jeremic B, Elgamal A, Yang Z, Lu J, Arduino P, McKenzie P, Deierlein G, Law K (2000) Open System for Earthquake Engineering Simulation (OpenSEES). http://opensees.berkeley.edu/

Mohle J, Kunnath S (2006) Reinforcing Steel: OpenSees User's Manual, 112-114. http://opensees.berkeley.edu/

Park YJ, Ang AH, Wen YK (1987) Damage-limiting aseismic design of buildings. Earthq Spectr 3(1):1-26

Priestley MJN, Calvi GM, Kowalsky M (2007) Displacement-based seismic design of structures, 1st edn. IUSS Press, Pavia, pp 193-194

Scott MH, Fenves GL (2006) Plastic hinge integration methods for force-based beam-column elements. ASCE J Struct Eng 132(2):244-252

Suarez LE, Montejo LA (2007) Applications of the wavelet transform in the generation and analysis of spectrum-compatible records. Struct Eng Mech 27(2):173-198

Vidot-Vega AL, Kowalsky MJ (2011) Impact of seismic input on strain/displacement response of rc members and frames. ACI Struct J 108(2):178-187

Wong K (2002) Inelastic seismic response analysis based on energy density spectra. J Earthq Eng 8(2):315-334

15WCEE Blind Test Challenge Preliminary Report (2012) 15th World Conference on Earthquake Engineering. Lisbon

15WCEE Blind Test Challenge Design Report (2012) 15th World Conference on Earthquake Engineering. Lisbon 